\title{
A política comercial da administração Bush: o CAFTA-DR e a resistência interior
}

Bush's trade policy: the CAFTA-DR and the inner resistence

THIAGO LIMA*

Rev. Bras. Polít. Int. 52 (1): 167-184 [2009]

\section{Introdução}

A política comercial dos EUA sofreu uma modificação importante sob a administração Bush. O país incorporou com assiduidade uma estratégia de proliferação de acordos de livre-comércio, deixando para trás a tradição quase exclusivamente multilateral do pós II Guerra. O acordo com Costa Rica, Guatemala, Nicarágua, Honduras, El Salvador e República Dominicana - o CAFTA-DR - é um deles. Apesar do pequeno impacto econômico para os EUA, esse foi o acordo comercial de mais difícil ratificação da história do país. Como entender esse episódio? Por que os EUA quase abortaram uma iniciativa que, considerando a assimetria de poder, parecia não ser tão desgastante? Sem menosprezar a capacidade negociadora dos interlocutores norte-americanos, argumentaremos que a principal resistência à iniciativa se encontrava dentro dos EUA.

O objetivo desse artigo é analisar, com ênfase em fatores domésticos, a dificuldade de os EUA aderirem ao CAFTA-DR. Esse exercício, que se torna oportuno devido à aproximação do encerramento da administração Bush (20012008), busca fornecer subsídios para reflexões sobre esse período em duas frentes: a política comercial norte-americana em sentido geral e as relações entre os EUA e a América Latina. Para tanto, na primeira seção, delineamos as linhas gerais da política comercial da administração Bush. Na segunda, inserimos o CAFTA-DR no contexto da primeira seção. Por fim, na terceira seção, analisamos o debate para a ratificação do acordo, destacando três fatores domésticos principais: a relação de forças sociais, a polarização partidária e a potencialização de interesses protecionistas, particularmente o setor do açúcar.

\section{A política comercial na administração Bush}

Uma das críticas de George W. Bush aos seus adversários Democratas na campanha presidencial de 2000 era a incapacidade deles obterem o fast-track

\footnotetext{
* Mestre pelo Programa 'San Tiago Dantas' de Pós-Graduação em Relações Internacionais (Unesp, Unicamp, Puc-SP) e pesquisador do Centro de Estudos Contemporânea - CEDEC (thiagomasi@uol.com.br).
} 
e de concluírem acordos de liberalização comercial multilaterais, regionais e bilaterais. $\mathrm{Na}$ verdade, Clinton havia concluído negociações bilaterais com a Jordânia em 2001 e iniciou negociaçôes com Singapura e Chile em 2000, mas o candidato Republicano considerava esses esforços tímidos. Paralelamente, não havia uma Rodada da OMC em negociação e as iniciativas regionais nas Américas e no Pacífico registravam poucos avanços. Era preciso retomar a liderança da liberalização comercial mundial.

No poder, a administração Bush reiterou a disposição em negociar acordos de livre-comércio em diversos níveis. Ao apresentar a agenda comercial da administração em 2001, Robert Zoellick, chefe do USTR, se queixou de que "enquanto existem aproximadamente 130 acordos de livre-comércio globalmente, os EUA são parte de apenas dois: um com o Canadá e o México (Nafta) e outro com Israel". E condenou "a ausência dos EUA da proliferação de acordos comerciais" (USTR, 2001: 4). Para resolver essa falha, afirmou que os EUA deveriam negociar em "múltiplas frentes" (idem).

A idéia de promover acordos de livre-comércio bilaterais não era algo simples para a tradição da política comercial norte-americana, predominantemente multilateral (Vigevani et al., 2007). Porém, o ideário de maximizar o emprego do poder norte-americano e, nesse sentido, a convicção de que agir sozinho pode ser necessário e desejável, ajuda entender os esforços bilaterais diante dos impasses da Rodada Doha e da negociação da Alca. As afirmações de Zoellick em hearings no Congresso deixam isso evidente:

agir em frentes múltiplas nos permitiu tomar o fato de que os EUA começam com 25 porcento da economia mundial e usar isso. Também significa que não permitiremos que nenhum outro país nos bloqueie, de modo que se nós estamos nas negociaçôes da $\mathrm{OMC}$ e 1 de 144 países decide nos parar, nós não possamos seguir. Francamente, também nos permite dar o ritmo ao invés de sermos reativos (Ways and Means, 2003: 13).

Argumentando especificamente sobre as dificuldades de concluir a Alca e a estratégia alternativa concluir de acordos bilaterais e regionais, Zoellick afirmou: "Há uma clara mensagem, que nós tentaremos fazer isso [acordo de livre-comércio] hemisférico, mas se não pudermos, trabalharemos com aqueles que querem" (Ways and Means, 2004: 13). Na América Latina foram concluídos acordos com: Chile, implementado em 2004; Costa Rica, El Salvador, Guatemala, Honduras, Nicarágua e República Dominicana - o CAFTA-DR, plenamente ratificado em 2007; Peru, ratificado em 2007; Colômbia, assinado em 2006; Panamá, assinado em 2007.

Embora a proliferação tenha correspondido à proposta da administração, não se pode afirmar que ela tenha tido sucesso completo, pois a Bolívia, o Equador e o Mercosul, com destaque para o Brasil em função do tamanho de sua economia, 
repudiam a agenda comercial norte-americana. $\mathrm{O}$ caso da Colômbia é o mais delicado. Amplamente desejado pela administração como parte do fortalecimento da parceria estratégica com o país andino, acordo sofre oposição praticamente imbatível no Congresso.

De fato, desde o início dos anos 90 os EUA possuem o objetivo de promover uma área de livre-comércio hemisférica, mas o que queremos ressaltar é que a atuação em diversos níveis de negociação - multilateral, regional e bilateral - é uma inovação que, "apesar das dificuldades em que tropeçou, tanto dentro quanto fora dos EUA, esta estratégia tem permitido à Washington se converter no eixo central de uma nova geração de acordos de livre-comércio" (Russel, 2006: 53). Um eixo central, mas de atratividade limitada.

Dois elementos dessa estratégia chamam a atenção. $\mathrm{O}$ primeiro é o building blocks. Diante da impossibilidade de avançar a liberalização comercial na direção pretendida pelos EUA no nível multilateral, passa-se a negociar nos níveis regional e bilateral, de modo a ir disseminando a agenda norte-americana. $\mathrm{O}$ segundo elemento é a 'liberalização competitiva'. Por meio dela, governos parceiros dos EUA procuram tornar seus estados mais competitivos do que os outros "assegurando acesso preferencial a mercados-chaves e, mais importante, vinculando reformas domésticas através de obrigações contratuais, melhorando assim o clima para investimento em seus mercados" (Schott, 2004: 362).

Um fator importante que se soma ao elemento da liberalização competitiva, e talvez seja até seu principal propulsor nos países andinos e da América Central e do Caribe na busca por acordos comerciais fora da Alca, era a possibilidade de não renovação das preferências comerciais unilaterais concedidas pelos EUA a esses países como uma forma de assistência. De fato, a Iniciativa para a Bacia do Caribe, destinada aos países da América Central e Caribe e a lei de Preferências Comerciais Andinas estavam programadas para expirar ao final de 2008 e 2006, respectivamente (Lek, 2005; Storrs, 2005). Para não perdê-las, muitos desses países buscaram acordos de livre-comércio.

Além de visar temas puramente comerciais, a política comercial norteamericana está atrelada a objetivos de política externa, de segurança e de política doméstica. Schott (2004: 363) aponta que além dos objetivos estritamente econômicos, há o intuito de promover o "estado de direito, fortalecer as fundaçôes da governança democrática e assegurar apoio aos esforços globais contra o terrorismo". Na mesma linha, Feinberg (2003: 1027) sustenta que os EUA

"esperam que um Hemisfério Ocidental integrado gere externalidades positivas ou spillover numa série de questōes transfronteiriças de preocupação comum, de contraterrorismo à contra-narcóticos, de proteção ambiental a cooperação energética".

Alguns vão mais além e apontam objetivos políticos e de segurança como sendo os principais motivos para a negociação dos acordos comerciais com 
economias pequenas (Rosen, 2004). Para Salazar-Xirinachs e Granados (2004: 233), embora o CAFTA-DR seja importante para alguns setores empresariais norte-americanos, o valor da América Central não deve ser exagerado no conjunto maior dos interesses empresariais dos EUA, levando à percepção de que "objetivos e motivações geopolíticas e de segurança são parte essencial desse acordo particular". Por fim, a importância dos grupos latino-americanos e temas a eles relacionados para as eleições nos EUA colocam os acordos comerciais na agenda de política doméstica (Lowenthal, 2006).

O contexto político doméstico norte-americano inóspito aos acordos de livrecomércio com a América Latina denota a relevância atribuída pela administração a esse instrumento político. A negociação e a ratificação do Nafta (Acordo de Livre-Comércio da América do Norte) na primeira metade dos anos 90 resultaram possivelmente na maior politização doméstica da história da política comercial dos EUA (Mundo, 1999; Destler, 2005). O principal elemento de politização doméstica decorreu de o Nafta ser o primeiro acordo abrangente a ser negociado com um país não desenvolvido, de leis trabalhistas e ambientais consideradas pouco avançadas e de baixos salários comparados aos pagos nos EUA. O Big Business apoiava a iniciativa, mas grupos ambientalistas e sindicatos se mobilizaram fortemente em oposição ao acordo regional. Os ambientalistas temiam a erosão dos padrões de proteção ambiental nos EUA ou que o México se tornasse um santuário para empresas norte-americanas poluidoras. Os sindicatos temiam uma competição mais direta com um país de baixos salários, assim como a transferência de fábricas norte-americanas para aproveitar os baixos salários mexicanos. Essas posiçóes tomaram contornos partidários, com a maioria dos Republicanos representando a posição do empresariado e a maioria dos Democratas advogando os interesses de grupos ambientalistas e sindicatos. Após duros debates e grandes esforços da administração Clinton o Nafta foi ratificado pelo Congresso, mas deixou seqüelas políticas domésticas: a aversão a negociação de acordos de livre-comércio com países latino-americanos e principalmente a dificuldade em lidar com temas ambientais e trabalhistas na agenda comercial (Destler e Balint, 1999). Essas seqüelas explicam boa parte da falha de Clinton em obter a renovação do fast-track (atual TPA) junto ao Congresso, sem o qual a administração tem poderes e credibilidade reduzidos para negociar acordos de livre-comércio.

O que se quer assinalar aqui é que a política comercial foi selecionada pela administração Bush como um dos principais meios de relacionamento com os países do hemisfério, principalmente os centro-americanos. Nas palavras de Zoellick, "conectamos o comércio a alguns outros objetivos, não somente crescimento global, mas desenvolvimento, expansão do estado de direito, sociedades abertas e os valores que de fato estão no coração do nosso país e sistema político" (Ways and Means, 2003: 13). Para viabilizar o emprego desse instrumento foi necessário obter autorização do Congresso, o que ocorreu em 2002 com a Trade Promotion Authority Act. 
O debate doméstico em torno do TPA não foi simples. A aprovação ocorreu por margem apertada na Câmara ( 215 a 212 votos), embora no Senado tenha sido mais folgada (64 a 34 votos). Isso deriva em sua maior parte de dois fatores vinculados diretamente à política doméstica (Destler, 2005). Primeiro, da relação de forças sociais. Há forte mobilização de grupos trabalhistas, ambientalistas e, em menor escala, de direitos humanos, que se opóem a uma maior integração da economia norte-americana à mundial se não houver regras que protejam seus interesses. Os grandes grupos empresariais, que em geral favorecem o livre-comércio, ou no mínimo não reivindicam um protecionismo de grandes proporçôes, com algumas exceções, não desenvolvem por conta própria uma campanha sistemática em prol da liberalização. Segundo, a crescente polarização partidária. O primeiro fator é basicamente o mesmo mencionado no debate do Nafta e dispensa aprofundamento. Mas para o segundo é preciso fazer um breve comentário.

O comportamento dos congressistas norte-americanos, principalmente para fins analíticos, é reportado pela literatura como accountable em boa medida aos grupos eleitoralmente relevantes. Historicamente, os políticos do Partido Democrata, incluído o presidente ou os presidenciáveis, identificaram-se com os grupos trabalhistas, ambientais e de direitos humanos de maneira muito mais intensa que os Republicanos. Estes, por sua vez, são mais associados ao empresariado, que teme o aumento da regulamentação estatal e a diminuição da exploração de vantagens comparativas obtidas pela transnacionalização das operações.

A política comercial não é o principal motivo da polarização partidária. Essa seria derivada de outros fatores mais arraigados na política doméstica. Um deles seria mudança nas preferências da população, que veio se tornando mais conservadora desde os anos 70. Outro seria o redesenho obrigatório dos distritos congressuais. De dez em dez anos, após o censo, as legislaturas estaduais devem redesenhar os distritos nos quais concorrem os candidatos para o Congresso nacional de modo que os distritos reflitam uma distribuição mais equânime da população. Assim, quando possível, legislaturas procuram remodelar os distritos para acomodar eleitorados fiéis a um partido (Bowler, Donovan e Heerde, 2006). Além disso, partidos e lideranças políticas se tornaram mais ideológicos nas últimas décadas e as duas últimas eleições presidenciais refletem a polarização (Destler, 2005).

Com a exacerbação da polarização partidária, ficou dificultada a formação de uma coalizão política doméstica capaz de agregar preferências sob um instrumento de concessão de autoridade ao presidente, algo necessário em um sistema decisório que Hermann e Hermann (1989: 364) denominariam como sendo de múltiplos atores autônomos, isto é, um sistema em que

os atores necessários [para a decisão] são indivíduos, grupos ou coalizões que, se alguns ou todos concordarem o governo pode agir, mas nenhum isoladamente tem a habilidade de decidir e forçar aceitação pelos outros; além disso, não existe um órgão de autoridade superior do qual todas as partes necessárias façam parte (Hermann e Hermann, 1989: 364). 
Nas palavras de Destler (2005: 282) "O presidente Bush e o USTR Zoellick conseguiram a autorização para negociação, mas não os amplos consenso e mandato que foram fornecidos aos seus predecessores". O 'Bipartisan' Trade Promotion Authority foi aprovado sobre considerável base partidária, com a cooperação de apenas 25 Democratas. Ajudaram o capital político acumulado pelo presidente em decorrência do 11 de Setembro e, principalmente, pesados side payments para obter os votos necessários, como a salvaguarda tarifária imposta sobre as importaçōes de aço, a promessa de negociar regras de origem mais rígidas para a importação de têxteis, e a complacência com os vultuosos subsídios da Farm Bill de 2002 (Bergstein, 2002). Tradicionalmente, a obtenção da autorização comercial pelo presidente junto ao Congresso é acompanhada de compensaçōes. A diferença para o TPA é que as concessóes protecionistas anteriores compunham amplas coalizóes domésticas, bipartidárias, que se refletiam em boas margens de ratificação dos acordos comerciais. Como a função do TPA é agregar preferências que deverão ser projetadas no exterior, é de se esperar que acordos que coincidam com aquelas preferências que aprovaram a autorização comercial enfrentem dificuldades similares para a ratificação, desde que a estrutura de preferências doméstica permaneça estável. Isto é, mesmo contando com eventual maioria Republicana, "Uma vez que a vitória foi construída sobre um número de Republicanos votando contra seus eleitorados e convicçôes, coloca-se em dúvida a habilidade do USTR em ganhar a aprovação de acordos comerciais controversos no futuro" (Destler, 2005: 332). A dificuldade em ratificar o CAFTA-DR expôs a divisão política doméstica. Contudo, um estudo comparativo sobre a ratificação de outros acordos bilaterais é necessário para sedimentar a questão.

\section{O CAFTA-DR}

O CAFTA-DR é expressão da política comercial norte-americana delineada na seção anterior. Faz parte de duas estratégias específicas inauguradas na administração Bush: a liberalização competitiva e a building blocks. Do ponto de vista comercial, busca igualar ou melhorar as oportunidades para empresas norteamericanas, já que os países da América Central têm acordos de livre-comércio com Chile, República Dominicana, México e Canadá, além de acordos de investimentos com países europeus e latino-americanos. Adicionalmente, é um instrumento da política externa para a América Latina. Trata também de ameaças consideradas de baixa intensidade, como tráfico de drogas, imigração, corrupção, pois é tido como um meio para fortalecer e aprimorar o estado de direito, aumentar a influência política norte-americana e expandir oportunidades econômicas. $\mathrm{O}$ depoimento de Noriega em defesa da ratificação do CAFTA-DR salienta a importância do acordo para a administração Bush. 
A formação de um Acordo de Livre-Comércio com a América Central e a República Dominicana tem sido uma de nossas prioridades diplomáticas nos últimos dois anos e meio. Acreditamos que a eliminação de barreiras comerciais podem ser um processo de transformação de sociedades. Ao estimular o crescimento, tornar os processos decisórios econômicos mais transparentes e ao abrir novas oportunidades econômicas para trabalhadores, fazendeiros e empresários, o livre-comércio não somente aumenta a prosperidade, mas fortalece a democracia. Isso aumenta a segurança dos EUA. A pobreza esmagadora é uma das causas da instabilidade política, da migração e do crime na América Central e na República Dominicana. É melhor atacar esses problemas na fonte do que ter que lidar com eles quando eles atingirem nosso litoral pela imigração ilegal, tráfico de drogas ou terrorismo (Western Hemisphere, 2005: 14).

Os governantes dos países centro-americanos e da República Dominicana defendem o CAFTA-DR como uma oportunidade de melhorar a inserção econômica internacional. Ele substitui e consolida boa parte das preferências comerciais unilaterais concedidas pelos EUA a esses países por meio do SGP, do Caribbean Basin Economic Recovery Act e do Caribbean Basin Trade Partnership Act, muitas das quais precisavam ser renovadas periodicamente pelo Congresso, além de liberalizar partes adicionais de comércio. Seria também estímulo à solidificação e aprimoramento das reformas neoliberais em marcha há cerca de duas décadas. Tal posição, apoiada por muitos segmentos sociais, principalmente o empresarial, obviamente não é isenta de críticas e de oposição, como demonstram os debates ocorridos durante os processos de negociação e ratificação nos parceiros norte-americanos (Condo, Colburn e Rivera, 2005; Jaramillo e Lederman, 2005; Hornbeck, 2007).

O CAFTA-DR é um acordo de liberalização comercial regional em que cada membro, apesar de ter um cronograma próprio para eliminar as barreiras ao acesso ao seu mercado, está sujeito aos mesmos compromissos ${ }^{1}$. É um acordo abrangente, pois liberaliza e estabelece regras para compras governamentais, propriedade intelectual, serviços, investimentos e mercadorias. Aborda também questôes ambientais e trabalhistas. O CAFTA-DR não afeta subsídios domésticos à agricultura e aborda pouco de subsídios à exportação. $\mathrm{O}$ compromisso é de não subsidiar as exportaçôes para os membros do acordo, a não ser quando em competição com exportações subsidiadas de terceiros. No que toca a mercadorias, a maior parte passou a ser comercializada isenta de tarifas logo após o acordo entrar em validade. Porém, alguns produtos sensíveis, principalmente os agrícolas, possuem um cronograma de abertura maior e mais lento, que poderia chegar a 20

1 A proposta inicial era a de negociação dos países centro-americanos em bloco com os EUA. Aqueles negociavam entre si, formulavam uma proposta comum e utilizavam-na na negociação. Porém, na quarta das nove rodadas de negociação a Guatemala decidiu adotar uma posição autônoma e a Nicarágua fez o mesmo na quinta rodada. 
anos. Alguns desses produtos são batatas e cebolas importadas pela Costa Rica, milho branco importado por Guatemala, El Salvador, Nicarágua e Honduras e o açúcar importado pelos EUA. Esses produtos continuarão sujeitos a quotas, que serão aumentadas anualmente em 2\% após um certo período (Hornbeck, 2007; Jaramillo e Lederman, 2005).

A ratificação do CAFTA-DR foi difícil e gerou um debate amplo. No Senado, foi aprovado por 54 a 45 votos em 30 de junho de 2005 e na Câmara o acordo foi aceito por 217 a 215 votos em 28 de julho do mesmo ano. Foi o mais difícil da história da política comercial norte-americana em termos de construção de uma coalizão que viabilizasse a ratificação, superando inclusive o NAFTA. A exemplo deste último acordo, sindicatos e ambientalistas, representados em sua maioria por congressistas Democratas, se opuseram ao CAFTA-DR por causa do grau de regulação considerado insuficiente para os dois temas. Setores específicos, como o de têxteis, alguns produtores de manufaturas e os produtores de açúcar também desaprovavam o acordo (Destler, 2005).

Essa dificuldade pode causar surpresa em decorrência da assimetria entre os EUA, de um lado, e os centro-americanos e a República Dominicana de outro. Não é necessário detalhá-la; basta mencionar que enquanto cerca de $50 \%$ comércio dos seis países é feito com os EUA, eles representaram cerca de 1,5\% do comércio exterior norte-americano em 2004 (Hornbeck, 2007). O acordo tampouco tem capacidade de influenciar significativamente o conjunto da economia norteamericana. A United States International Trade Commission estimou que seu efeito seria de agregar $0,01 \%$ do produto nacional bruto para cada ano do acordo (Jaramillo e Lederman, 2005).

Apesar da assimetria, os cinco países da América Central e a Republica Dominicana são, em conjunto, os segundos maiores importadores dos EUA na América Latina, ficando atrás somente do México. As importações daqueles países são maiores do que as da Rússia, Índia e Indonésia combinadas. Antes do acordo, mais de $80 \%$ das exportaçóes dos membros do CAFTA-DR entravam nos EUA com tarifa zero, enquanto $40 \%$ das vendas norte-americanas recebiam esse tratamento. Isso confere ao arranjo uma certa importância para o fortalecimento das relaçóes comerciais no hemisfério, e por isso foi amplamente apoiado pelo empresariado. Porém, mesmo sendo apresentado pela administração com uma das mais importantes iniciativas para a América Latina, o CAFTA-DR quase não foi concretizado.

\section{A ratificação do CAFTA-DR e a questão do açúcar}

Um dos principais eixos do debate em torno da ratificação do CAFTA-DR, o principal do campo agrícola, foi a possibilidade de diminuição da política de proteção aos produtores de açúcar nos EUA. O que estava em jogo era a abertura do setor como moeda de barganha. Esse foi um desafio colocado pelos seis 
interlocutores dos EUA e, na interpretação dos produtores de açúcar, pela própria administração Bush ${ }^{2}$. A administração se defendeu argumentando que não havia risco de modificação da proteção ao setor por causa do CAFTA-DR. Contudo, se a estratégia de proliferação de acordos comerciais continuar no longo-prazo, a política de proteção ao açúcar terá de ser reformada ou mesmo extinta. Examinar a questão do açúcar neste caso ganha relevância por fornecer pistas às dificuldades domésticas que as futuras administraçōes norte-americanas terão ao buscar a liberalização do comércio internacional, sobretudo na área agrícola.

O compromisso norte-americano foi de paulatinamente aumentar a quota de importação de açúcar destinada aos parceiros (Olson, 2005). Antes do CAFTADR, os cinco países centro-americanos e a República Dominicana possuíam quotas isentas de tarifa sob o Acordo sobre Agricultura da OMC de, respectivamente, 126.365 toneladas métricas (tm) e $185.335 \mathrm{tm}$. Juntos, portanto, os seis países possuíam $311.700 \mathrm{tm}$ duty free, o que correspondia a 28\% dos 1,139 milhões de tm distribuídas pelos EUA para 41 países sob o Acordo de Agricultura. Com o CAFTA-DR, os norte-americanos concederam 99 mil toneladas métricas a mais para os centro-americanos no primeiro ano de validade do acordo, e $41 \mathrm{mil} \mathrm{tm}$ seriam adicionadas gradualmente ao longo de 15 anos. Já a República Dominicana teria um aumento de $10 \mathrm{mil}$ tm no primeiro ano e mais $2 \%$ anualmente sobre o valor adicional concedido no primeiro ano. Então, no início, a quota dos parceiros norte-americanos seria dilatada em $109 \mathrm{mil} \mathrm{tm}$, alcançando incremento de quase 465 mil tm ao longo de 15 anos, como demonstra a tabela 2. Estima-se que a produção centro-americana exportada para os EUA aumente de $4 \%$ para $8 \%$.

\section{Tabela 1}

Cronograma de ampliação de quotas ao açúcar no CAFTA-DR (toneladas métricas)

\begin{tabular}{|l|l|l|l|l|l|l|}
\hline $\begin{array}{l}\text { CAFTA sugar } \\
\text { import access }\end{array}$ & $\begin{array}{l}\text { Z003-04 } \\
\text { quota }\end{array}$ & $\begin{array}{l}\text { Increase } \\
\text { year 1 }\end{array}$ & $\begin{array}{l}\text { Increase } \\
\text { year 2 }\end{array}$ & $\begin{array}{l}\text { Increase } \\
\text { year 15. }\end{array}$ & $\begin{array}{l}\text { Total, } \\
\text { year 15 }\end{array}$ & $\begin{array}{l}\text { Annual increase } \\
\text { year 16 + }\end{array}$ \\
\hline Guatemala & 50,546 & 32,000 & 32,640 & 49,820 & 100,366 & +940 \\
\hline El Salvador & 27,379 & 24,000 & 24,480 & 36,040 & 63,419 & +680 \\
\hline Nicaragua & 22,114 & 22,000 & 22,440 & 28,160 & 50,274 & +440 \\
\hline Honduras & 10,530 & 8,000 & 8,160 & 10,240 & 20,770 & +160 \\
\hline Casta Rica & 15,796 & $\begin{array}{l}11,000 \\
2,000\end{array}$ & 13,220 & 16,080 & 31,876 & +220 \\
\hline $\begin{array}{l}\text { Dominican } \\
\text { Republic }\end{array}$ & 185,335 & 10,000 & 10,200 & 12,800 & 198,135 & +200 \\
\hline Total & 311,700 & 109,000 & 111,140 & 153,140 & 464,840 & $+2,640$ \\
\hline
\end{tabular}

NoTrs

2. DR-CAFTA TRQ increses vary from country to sountry from years 2-15.

b. Additional organic $2000 \mathrm{mt}$ TRQ allocated to Costa Rica.

Fonte: Olson (2005)

2 Agricultural Technical Advisory Committee for Trade in Sweeteners and Sweetener Products, (2004) The U.S.-Central American Free Trade Agreement (CAFTA). Em http://www.ustr.gov/assets/Trade_Agreements/ Bilateral/CAFTA/CAFTA_Reports/asset_upload_file97_5940.pdf, acesso em 30/01/2008. 
Segundo o USTR (2005a; 2005b), o incremento nas importações não terá capacidade para a afetar o programa de proteção ao açúcar norte-americano, explicado adiante. A projeção era de que no primeiro ano do acordo as importações de açúcar corresponderiam a cerca de $1,2 \%$ do consumo doméstico e, depois de 15 anos, chegaria a $1,7 \%$, portanto bastante pequena. Além disso, o acordo não prevê a eliminação das tarifas de mais de $100 \%$ para exportações que excederem as quotas e conta ainda com a possibilidade de impor salvaguarda à importação de açúcar mediante compensação equivalente.

Porém, os grupos de interesse ligados ao açúcar fizeram forte campanha de oposição ao acordo, afirmando que ele prejudicaria sim o programa norteamericano. $\mathrm{O}$ argumento central era que o aumento nas importações abalaria o terceiro pilar do programa de proteção ao açúcar, o que faria desmoronar a política protecionista para o setor. Para entender melhor o argumento é útil descrever brevemente o referido programa.

O programa de proteção ao açúcar instituído na Farm Bill de 2002 é uma variação do programa instituído pela primeira vez com a Lei Jones-Castigan de 1934. Na versão atual ${ }^{3}$, ele conta com três pilares: non-recourse loans; flexible marketing allotments (quotas domésticas) e Tariff-Rate Quotas (TRQ) (Olson, 2005; Haley e Ali, 2007). O objetivo é manter o preço doméstico em nível considerado 'justo', valendo-se da restrição da venda doméstica e do desestímulo a produção, de modo a impedir a superprodução, assim como bloquear importações a partir de uma certa quantidade para limitar a oferta interna.

O non-recourse loan é um tipo de empréstimo feito pela Commodity Credit Corporation (CCC) similar ao marketing assistance loan, ou seja, o Congresso estabelece um preço mínimo ao açúcar que equivalha aos custos de produção, mais os juros do empréstimo. Caso o preço de mercado caia abaixo daquele legislado, o empréstimo pode ser pago em açúcar ao invés de em dinheiro. O preço legislado (loan rate) para açúcar de cana-de-açúcar é de 18 centavos por libra e de 22,9 centavos por libra por açúcar de beterraba refinado domesticamente ${ }^{4}$. O açúcar repassado à CCC não é comercializado por um certo período para que o preço de mercado seja elevado. A estocagem é feita pelo processador, que recebe pagamento do governo por isso. É interessante notar que os empréstimos são feitos aos processadores e não aos produtores de açúcar, mas os ganhos obtidos pela diferença entre os preços de mercado e o preço estabelecido pelo Congresso, a loan rate, deve ser dividido entre produtores e processadores. Os empréstimos devem ser pagos em no máximo nove meses, com juros, de modo a garantir o autofinanciamento do programa.

O Flexible Marketing Allotments é um instrumento conferido ao secretário de Agricultura para limitar as vendas domésticas de açúcar, por meio de quotas

3 Título I, Subtítulo D da Farm Security and Rural Investment Act of 2002.

4 Seção 1401 da Farm Security and Rural Investment Act of 2002. 
distribuídas aos processadores. $\mathrm{O}$ açúcar produzido em excesso à quota não pode ser vendido domesticamente e o produtor deve estocá-lo, arcando com tais custos. Isso porque o USDA estima a demanda doméstica e a quantidade necessária para atendê-la visando a manutenção do preço.

Por fim, a oferta no mercado doméstico é controlada pela TRQ. Com ela, os EUA permitem a importação de açúcar isenta de tarifas de 41 países, algo em torno de $13 \%$ do consumo interno. O teto estabelecido pelo Congresso é de 1,39 milhões de tm para importaçóes. Se ele for ultrapassado, o USDA perde a autoridade de controlar as vendas domésticas ${ }^{5}$. Com isso, muito provavelmente ocorreria superprodução e queda dos preços domésticos abaixo da loan rate, prejudicando produtores e aumentando os gastos governamentais com esse programa que, sob condições normais, não tem custo direto para o governo.

Assim, o cerne da queixa dos produtores de açúcar norte-americanos era que a expansão da quota dos países centro-americanos seria um passo na direção da superação do teto de importação estabelecido pelo Congresso. Na verdade, as quotas atuais fornecidas pelos EUA são de 1,13 milhões de tm e a diferença entre este valor e o teto legislado, $260 \mathrm{mil} \mathrm{tm}$, é uma reserva (buffer) que se teme perder por duas razóes (Olson, 2005; Haley e Ali, 2007). Primeira, a partir de 2008 o México poderá exportar quantidades ilimitadas de açúcar aos EUA sob o NAFTA. Segunda, uma vez que a proliferação de acordos comerciais é uma estratégia enfatizada pela administração, há o receio de que novos acordos bilaterais e regionais tragam benefícios adicionais que, acumuladas, poderão por o terceiro pilar em risco e levar todo o programa a pique. Nas palavras de Jack Roney, diretor de economia e análise política da American Sugar Alliance, "no longo-prazo, o CAFTA-DR é apenas a ponta do iceberg. Atrás dos países do CAFTA-DR, 21 outros países exportadores estão (...) esperando para fazer acordo com os EUA" (Ways and Means, 2005: 130). Daí os esforços pela rejeição do CAFTA-DR: "consideramos o CAFTA-DR uma questão de vida ou morte" (Ways and Means, 2005: 130). Esta segunda razão é de fato um desafio à política agrícola norteamericana, como demonstra o gráfico 1 abaixo. $\mathrm{O}$ aumento do acesso ao mercado norte-americano concedido aos parceiros do acordo não ocorrerá em detrimento dos outros países que usufruem das quotas.

$\mathrm{O}$ acordo foi ratificado com concessões limitadas aos centro-americanos e à República Dominicana. De fato, o açúcar foi o único produto agrícola com tratamento especial pelos EUA. Não se pode ignorar que parte de explicação para a abertura limitada pode ser encontrada na própria dinâmica da negociação, na troca de concessões. Anabel González (2006: 29), que foi negociadora-chefe da Costa Rica, relata que

5 Na seção 1403 da Farm Security and Rural Investment Act of 2002, o teto é de 1.532 milhōes de short tons, equivalentes à quantidade mencionada em $\mathrm{tm}$. 
"desde as primeiras trocas de ofertas ficou evidente que a dificuldade que se apresentava nesta área [agrícola], sobretudo para a América Central, se manifestava pelo alto grau de correlação entre os produtos prioritários dos EUA e os produtos sensíveis para os países da região. O inverso ocorria em muitos poucos casos, sobretudo, com açúcar”.

Segundo ela, os centro-americanos tinham interesse em manter diversos produtos sob regime de exceção, enquanto a posição norte-americana era de que todos tivessem tratamento igual. Posteriormente, um maior acesso ao mercado norteamericano de açúcar foi colocado como condição para diminuição das exceções demandadas pelos centro-americanos. De grande relevância para aumentar as quotas centro-americanas foi a retirada do arroz da lista de exceção costarriquenha, algo que os negociadores dos EUA consideravam um trunfo para a ratificação doméstica. Ao final da negociação, o capítulo sobre agricultura foi concluído com as exceçôes e salvaguardas mencionadas anteriormente. Todos os sete países mantiveram protegidos alguns produtos agrícolas específicos. O que queremos salientar é que a barganha foi um elemento que levou o Executivo a buscar aumentar o acesso ao mercado norte-americano de açúcar, ou mesmo possibilitou essa busca.

\section{Gráfico 1 \\ Potencial de exportação de açúcar de países negociando TLC com os EUA (milhões de tm. média de 2002-2004)}

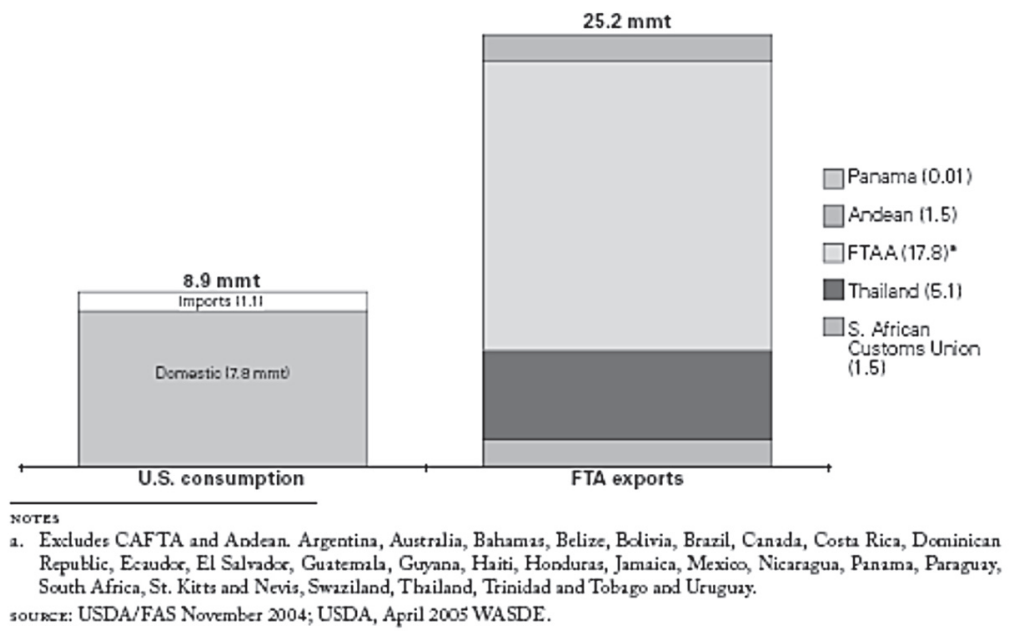

Fonte: Olson (2005)

Mas outra parte da explicação reside em boa medida nos esforços dos grupos de interesse e congressistas vinculados ao setor do açúcar. Para tratar melhor a questão, deve-se colocá-la na perspectiva geral de ratificação do acordo, o que nos 
possibilitará analisar a força desses grupos e o TPA como mecanismo capaz de agregar preferências liberalizantes. Na verdade, apesar de não ter havido abertura completa ao setor de açúcar, consideramos que os interesses protecionistas norteamericanos saíram derrotados.

A estrutura de preferências doméstica ajuda a analisar a questão (Milner, 1997). Utilizando os relatórios que comitês de aconselhamento (compostos por representantes da sociedade e alocados institucionalmente no USTR) emitem com opinião sobre a ratificação do acordo comercial, podemos afirmar que a administração Bush e os congressistas que a apoiavam buscavam deslocar o status quo no sentido da liberalização, apoiados principalmente por empresários. Deve-se notar que indústrias que utilizam açúcar como insumo estavam entre esses apoiadores $^{6}$. A coalizão de oposição rejeitava o deslocamento do status quo nessa direção por alguns motivos. Para os sindicatos, o acordo não promovia o aperfeiçoamento das leis trabalhistas, não continha mecanismos adequados para garantir que os compromissos trabalhistas fossem cumpridos e as regras para serviços, investimentos e licitações prejudicavam a capacidade dos governos parceiros agirem pelo interesse público ${ }^{7}$. A maioria dos ambientalistas endossou o acordo, opinando que o CAFTA-DR atingia os objetivos do Congresso escritos no TPA e que aperfeiçoaria a proteção do meio ambiente ${ }^{8}$. Houve, contudo, forte oposição da minoria e uma série de reservas, por exemplo, sobre a falta de financiamento adequado à capacitação da preservação ambiental, mecanismos de solução de controvérsias entre empresa e Estado que fortaleciam inadequadamente os primeiros em detrimento da boa governança, e salvaguardas ambientais de baixa eficiência. É importante destacar que o setor agrícola apoiou o acordo, com exceção dos produtores de açúcar, mas frisando que a negociação da liberalização da agricultura deve ocorrer preferencialmente no âmbito multilateral ${ }^{9}$.

6 Advisory Committy for Trade Policy and Negotiations (2004), The U.S.-Central America Free Trade Agreement(CAFTA).Em http://www.ustr.gov/assets/Trade_Agreements/Bilateral/CAFTA/CAFTA_Reports/ asset_upload_file367_5932.pdf, acesso em 30/1/2008. Para um debate entre fornecedores e consumidores de açúcar como insumo, ver a transcrição do hearing conduzido pelo Comitê de Ways and Means (2005).

7 Labor Advisory Committy for Trade Negotiations and Trade Policy, (2004) The U.S.-Central America Free Trade Agreement (CAFTA). Em http://www.ustr.gov/assets/Trade_Agreements/Bilateral/CAFTA/ CAFTA_Reports/asset_upload_file63_5935.pdf, acesso em 30.01.2008.

8 Trade and Environment Policy Advisory Committy, (2004) The U.S.-Central American Free Trade Agreement. Em http://www.ustr.gov/assets/Trade_Agreements/Bilateral/CAFTA/CAFTA_Reports/ asset_upload_file789_5933.pdf, acesso em 30/01/2008. É interessante notar que no item B.2.g do Relatório do TEPAC os ambientalistas reclamaram que as quotas adicionais aos países do CAFTA-DR deveriam ter sido muito maiores. Para eles, a maior importação diminuiria a produção de açúcar em áreas ambientais sensíveis, como o Everglades, na Flórida.

9 Agricultural Policy Advisory Committee, (2004) The U.S. -Central America Free Trade Agreement. Em http:// www.ustr.gov/assets/Trade_Agreements/Bilateral/CAFTA/CAFTA_Reports/asset_upload_file70_5936.pdf, acesso em 30/01/2008. O apoio do setor agrícola em geral pode ser entendido como decorrente das crescentes oportunidades comerciais nos países do CAFTA-DR. De 1995 a 2004, exportações de mercadores dos EUA para a região aumentaram $74 \%$, totalizando US \$ 15,7 bilhōes e importações cresceram $91 \%$, somando US \$ 17,7 bilhōes. Exportaçōes agrícolas cresceram 56\%, somando US \$1,71 bilhāo e importaçōes cresceram 23\%, totalizando US \$ 2,47 bilhōes (Paggi et al, 2005). 
A polarização entre as duas coalizões foi significativa e a cooptação de membros da oposição pela administração demandou uma série de compensações e trocas políticas (side-payments), assim como foi necessário para a aprovação da TPA. Vale mencionar algumas (Erikson, 2004/2005; Hornbeck, 2007). Para o Senado, o então chefe do USTR, Robert Portman, escreveu carta ao senador Democrata Jeff Bingaman, prometendo que o Executivo buscaria, junto ao Congresso, alocar US\$ 40 milhōes do orçamento para operações estrangeiras em projetos de capacitação de aplicação de padrões trabalhistas e ambientais por 3 anos, dos quais cerca de US \$ 3 milhões seriam destinados à Organização Internacional do Trabalho para a elaboração de relatórios sobre a aplicação daqueles padrōes nos parceiros do CAFTA-DR. Mais US\$ 10 milhões seriam destinados à República Dominicana, Guatemala e El Salvador para melhorias na área rural para que pudessem atingir elegibilidade ao programa U.S. Millennium Challenge Corporation. Para a Câmara, foi aprovada a U.S. Trade Rights Act, lei que aumenta as possibilidades de defesa comercial contra a China e economias que não são de mercado.

Concessões foram feitas especificamente para o setor têxtil, entre elas: modificar as regras de origem acordadas no CAFTA-DR para que bolsos e forros beneficiados pelo acordo fossem produzidos exclusivamente pelos membros e não provenientes de outros países; aumentar a quantidade necessária de tecido norteamericano nos produtos nicaragüenses para que pudessem ser isentos ao entrar nos EUA; e negociar com o México um novo acordo de controle aduaneiro para diferenciar têxteis importados do CAFTA-DR com insumos norte-americanos e mexicanos.

Para o setor do açúcar, Mike Johanns, Secretário de Agricultura, enviou carta aos presidentes dos Comitês de Agricultura da Câmara e do Senado, deputado Bob Goodlatte e o senador Saxby Chambliss, ambos Republicanos, afirmando o compromisso da administração em não permitir que o CAFTA-DR prejudicasse o programa de proteção ao açúcar estabelecido pela Farm Bill de 2002. No caso de as importações ultrapassarem o teto do terceiro pilar, as perdas dos produtores domésticos seriam compensadas com pagamentos diretos ou com a compra do açúcar para fins não alimentícios, tal como a produção etanol.

A polarização doméstica "torna a margem básica de apoio estreita, tornando a política comercial refém de qualquer interesse protecionista que possuam os votos marginais, decisivos", principalmente na Câmara dos Deputados (Destler, 2005:306). Isso explicaria a capacidade do setor de açúcar ser capaz de colocar sério obstáculo à ratificação do CAFTA-DR e limitar as concessões efetuadas, apesar de sua ineficiência, de lesar o consumidor e da baixa relevância para a economia nacional.

Por fim, é interessante notar que foi o procedimento de ratificação do TPA que potencializou e ao mesmo tempo criou uma condição necessária para a superação das restrições dos grupos protecionistas, não apenas do setor de açúcar, quanto ao deslocamento do status quo numa direção liberalizante. A potencialização ocorreu 
porque o Executivo colocou a adição de quotas aos parceiros do CAFTA-DR como uma concessão em um acordo de liberalização comercial. Surgiu oportunidade para os produtores de açúcar exercerem influência no processo legislativo, visto que a validade da concessão estava sujeita a ratificação. Segundo a Farm Bill de $2002^{10}$, cabe ao Executivo determinar e distribuir o total de quotas disponibilizadas entre os países elegíveis, levando em conta a estimativa de consumo doméstico, a capacidade dos produtores norte-americanos de suprir uma parte do consumo, os compromissos assumidos de importar 1,13 milhōes de tm. sob a TRQ, e o teto-gatilho de 1,39 milhões tm. Isto é, havendo perspectiva de crescimento do consumo de açúcar, o Executivo poderia ter aumentado as quotas de forma autônoma. Porém, deve-se salientar que, ao trocar o incremento das quotas de açúcar por outras vantagens em um acordo comercial, o Legislativo entrou no jogo. Ademais, a ratificação do incremento gradual das quotas dificulta a reversão sem ação legislativa.

Quanto à superação da oposição, o TPA é um instrumento institucional que permite aos congressistas superarem o protecionismo. O procedimento legislativo é responsável por isso. Em uma única votação, sem possibilidade de emendas, deve-se votar pela ratificação ou pela rejeição do acordo sem possibilidade de emendá-lo. Isso permite ao legislador votar pela liberalização argumentando ao seu eleitorado que, apesar de o acordo prejudicar alguns setores, expondo-os à competição, em geral, ele é benéfico ao conjunto da economia. Entretanto, como dissemos, essa posição é contingente às preferências dos congressistas à capacidade de construção de coalizões. O histórico de utilização desse instrumento permite afirmar que ele é um viesador em favor da liberalização comercial, pois jamais um acordo comercial deixou de ser ratificado. Contudo, as divisões políticas domésticas deixaram claro que sem o envolvimento de peso da administração Bush o CAFTA-DR poderia ter sido uma exceção.

\section{Conclusão}

A proliferação de acordos comerciais na administração Bush representou uma mudança na tradição norte-americana. De algo fundamentalmente multilateral, passou a ser bilateral. Com a aproximação do encerramento da administração Bush, parece razoável avaliar essa política como de sucesso parcial no que toca à América Latina. No caso do CAFTA-DR, como pudemos observar, houve grande dificuldade para que o acordo fosse ratificado. Essa dificuldade surpreende porque o impacto que a regiāo é capaz de produzir na economia dos Estados Unidos é pequeno e também porque a administração Bush atribuiu significativa relevância ao acordo. O Estado teve dificuldade para concretizar uma iniciativa que, considerando a assimetria entre os países, parecia não ser problemática.

10 Seção 1403. 
Dois fatores domésticos parecem ter sido relevantes para entender essa dificuldade. Primeiro, a crescente polarização partidária nos últimos anos, tornou mais complexa a criação de amplas coalizões legislativas no campo da política comercial. Conseqüentemente, esse é o segundo fator, as maiorias construídas são mais estreitas, o que potencializa a demanda de grupos protecionistas capazes de mobilizar uns poucos congressistas. Como esses congressistas podem ser decisivos, eles são capazes de extrair compensaçōes consideráveis sob a ameaça de bloquear a ratificação.

\section{Bibliografia}

BERGSTEIN, C. Fred. (2002) A renaissance for United States trade policy?. Foreign Affairs, novembro/dezembro.

BOWLER, Shaun, DONOVAN, Todd e HEERDE, Jennifer van. (2006) The United States of America: Perpetual campaigning in the absence of competition. Em GALLAGHER, Michael e MITCHELL, Paul (Eds.) The politics of Electoral Systems. Oxford: Oxford University Press.

CONDO, Arturo, COLBURN, Forrest e RIVERA, Luis. (2005). The United States - Central America Free Trade Agreement (CAFTA): negotiations and expected outcomes. CRS Report for Congress. Em <http://fpc.state.gov/documents/organization/20484.pdf>. Acesso em $7 / 1 / 2008$.

DESTLER, I. M. e BALINT, Peter J. (1999) The New Politics of American Trade: Trade, Labor, and the Environment. Institute for International Economy. Em <http://bookstore. petersoninstitute.org/book-store/106.html>, acesso em 13/10/2006.

DESTLER, I. M. (2005) American Trade Politics. Fourth Edition. Washington: Institute for International Economics.

ERIKSON, Daniel P. (2004/2005). Central America's free trade gamble. World Policy Journal. Winter.

FEINBERG, Richard E. (2003) The political economy of United States' free trade arrangements. The world economy, vol. 27, $\mathrm{n}^{\circ} \mathrm{T}$.

HALEY, Stephen e ALI, Mir. (2007). Sugar Backgrounder. Economic Research Service. USDA. Em http://www.ers.usda.gov/Publications/SSS/Jul07/SSS249/. Acesso em 01/01/2008.

HERMANN, Margareth G. e HERMANN, Charles F. (1989) Who makes foreign policy and how: an empirical inquiry. International Studies Quaterly, vol. 33 n4.

HORNBECK, J. F. (2007) The Dominican Republic-Central America-United States Free Trade Agreement (CAFTA-DR). CRS Report for Congress. Em <http://www.nationalaglawcenter. org/assets/crs/RL31870.pdf>. Acesso em 01/01/2008.

JARAMILLO, C. Felipe e LEDERMAN, Daniel. (2005) DR-CAFTA: Challenges and opportunities for Central America. Central America Department and Office of the Chief Economist Latin America and Caribbean Region. Em <http://lnweb18.worldbank.org/ LAC/LAC.nsf/ECADocbyUnid/3D4B4F71AE8214FE8525702D00710E58?Opendoc ument>. Acesso em 07/01/2008. 
LEK, Lenore (2005). Andean-U.S. free trade agreement negotiations. CRS Report for Congress. Em <http://www.usembassy.at/en/download/pdf/andean_trade.pdf >. Acesso em 07/02/2008.

LOWENTHAL, Abraham F. (2006). De la hegemonia regional a las relaciones bilaterales complejas: Estados Unidos y América Latina a principios del siglo XXI. Nueva Sociedad, no 206.

MILNER, Helen V. (1997) Interest, institutions and information. Domestic politics and international relations. Princeton: Princeton University Press.

MUNDO, Philip A. (1999) National politics in a global economy: The domestic sources of U.S. trade policy. Washington, DC: Georgetown University Press.

OLSON, R. Dennis. (2005) Sweet or sour? the U.S. sugar program and the threats posed by the Dominican Republic - Central American Free Trade Agreement. Institute for Agriculture and Trade Policy; Minneapolis.

ROSEN, Howard. (2004) Free trade agreements as foreign policy tools: The US-Israel and US-Jordan FTAs. Em SCHOTT, Jeffrey J. (ed) Free Trade Agreements: US Strategies and Priorities. Washington: Institute for International Economics.

SCHOTT, Jeffrey J. (2004). Assessing US FTA policy. Em SCHOTT, Jeffrey J. (ed) Free Trade Agreements: US Strategies and Priorities. Washington: Institute for International Economics.

SALAZAR-XIRINACHS, José M. e GRANADOS, Jaime. (2004) The US-Central América free trade agreement: opportunities and challenges. Em SCHOTT, Jeffrey J. (ed) Free Trade Agreements: US Strategies and Priorities. Washington: Institute for International Economics.

STORRS, K. Larry (coord.).(2005) Central America and the Dominican Republic in the context of the Free Trade Agreement (DR-CAFTA) with the United States. CRS Report for Congress. Em < http://www.house.gov/spratt/crs/RL32322.pdf>. Acesso em 07/02/2008.

PAGGI, Mechel S. et alli. (2005) Regional Trade Agreements and implications for US agriculture: the case of CAFTA-DR. Choices. The magazine offood, farm and resources issues. Vol. 2, no 20 .

RUSSEL, Roberto. (2006) América Latina para Estados Unidos: ¿especial, desdeñable, codiciada o perdida? Em Nueva Sociedad, n 206. Buenos Aires, novembro-dezembro.

USTR. (2001) The 2001 trade policy agenda and 2000 annual report of the president of the United States on the Trade Agreements Program. United States Trade Representative, Executive Office of the President.

. (2005a) The case for CAFTA. Growth, opportunity, and democracy in our neighborhood. CAFTA Policy Brief. Fevereiro. Em http://www.ustr.gov/assets/Trade_ Agreements/Regional/CAFTA/Briefing_Book/asset_upload_file235_7178.pdf. Acesso em 10/10/2005.

. (2005B) Sugar: a spoonful a week. CAFTA Policy Brief. Fevereiro. Disponível <http://www.ustr.gov/assets/Trade_Agreements/Bilateral/CAFTA/Briefing_Book/ asset_upload_file923_7210.pdf>, acesso em 10/10/2005

VIGEVANI, Tullo, et.al. (2007). Estados Unidos: Política comercial (USTR). em VELASCO E CRUZ, Sebastião C. Reestruturação econômica mundial e reformas liberalizantes nos países em 
desenvolvimento", vol. 4. Relatório final enviado à FAPESP, São Paulo / Campinas: CEDEC / UNICAMP.

WAYS AND MEANS, Committee on. (2003) President's Bush trade agenda. House of Representatives, Committee on Ways and Means, $108^{\circ}$ Congresso, $1^{\circ}$ sessão, Hearing no 108-12. Washington, D.C., 26 de fevereiro.

President's Bush trade agenda. (2004) House of Representatives, Committee on Ways and Means, $108^{\circ}$ Congresso, $2^{\circ}$ sessão, Hearing no $108-43$. Washington, D.C., 11 de março.

. Implementation of the Dominican Republic - Central American Free Trade Agreement (DR-CAFTA). (2005) House of Representatives, Committee on Ways and Means, 1090 Congresso, $1^{\circ}$ sessão, Hearing no $109-10$. Washington, D.C., 21 de abril.

WESTERN HEMISPHERE, Subcommittee on the. (2005) U.S. diplomacy in Latin America. House of Representative, Committee on International Relations. $109^{\circ}$ Congress, $1^{\circ}$ sessão, Hearing 109-122. Washington, D.C., 27 de julho.

Recebido em 5 de agosto de 2008 Aprovado em 20 de fevereiro de 2009

\section{Resumo}

Argumenta-se que a política comercial da administração Bush é uma importante modificação na tradição norte-americana ao aderir à proliferação de acordos bilaterais. Contudo, a análise do CAFTA-DR demonstra que ela pode encontrar forte resistência doméstica.

\section{Abstract}

It is argued that the Bush Administration's trade policy is an important change in the U.S. tradition because of the proliferation of bilateral agreements. However, the analysis of the CAFTA-DR demonstrates that it can found strong domestic resistance.

Palavras-chave: EUA; política comercial; CAFTA-DR; açúcar. Key words: USA; trade policy; CAFTA-DR; sugar. 